\title{
Arbeitsunfall mit dem eigenen Pkw - wer muss zahlen?
}

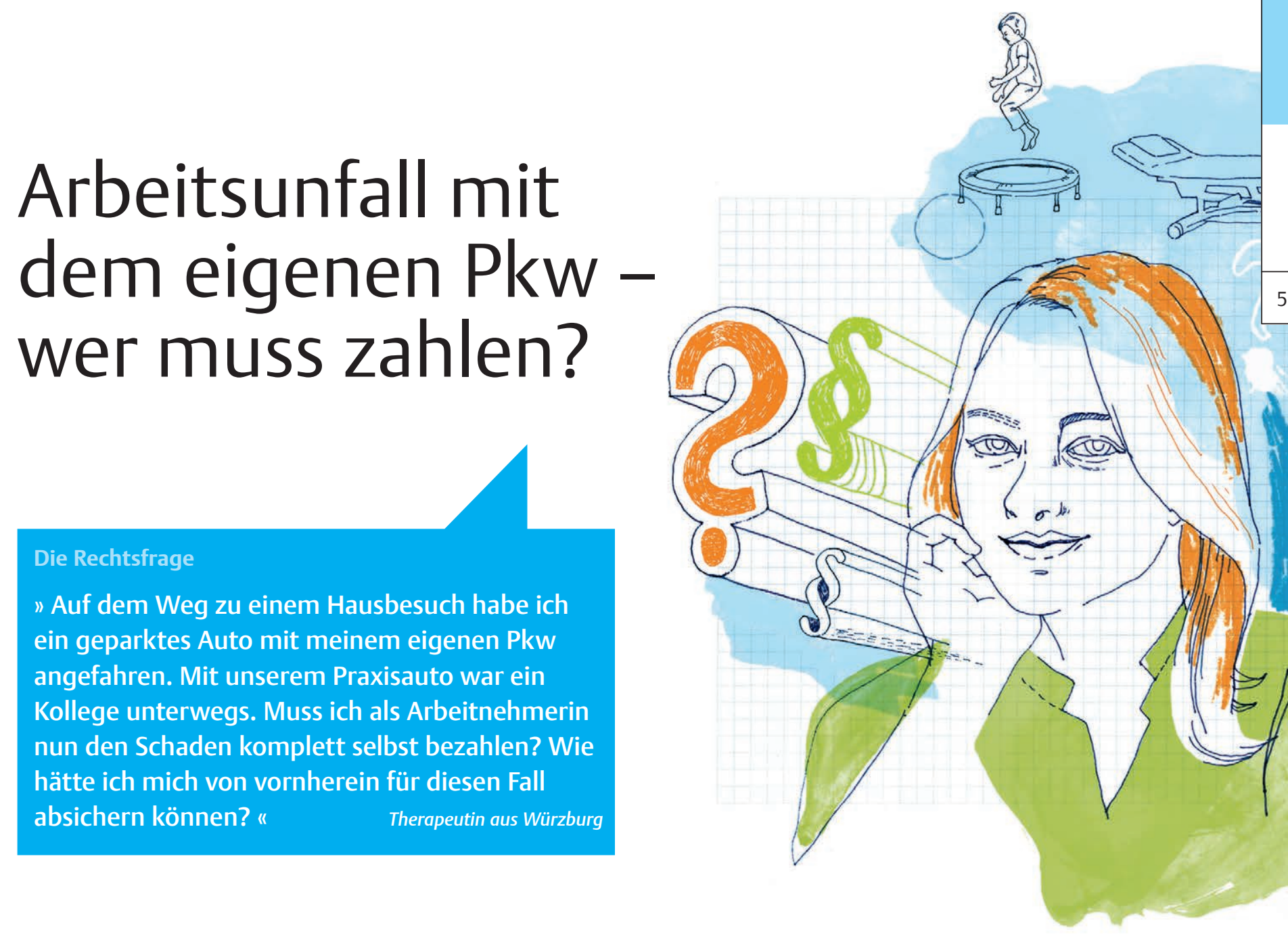

\section{Die Antwort unseres Experten}

Entsteht einem Arbeitnehmer während der Arbeit ein Schaden an persönlichen Dingen, ist zunächst festzustellen, ob der Schaden auf das allgemeine Lebensrisiko zurückzuführen ist. Das wäre zum Beispiel ein Stolpern auf der Treppe, sofern diese nicht schadhaft ist. In solchen Fällen trägt der Arbeitnehmer den Schaden allein. Liegt die Schädigung allerdings im Verantwortungsbereich des Arbeitgebers in der sogenannten betrieblichen Risikosphäre, haftet dieser.

In Ihrem Fall ist eindeutig der Risikobereich Ihres Arbeitgebers betroffen: Sie mussten mit Ihrem privaten Pkw einen Patienten aufsuchen. Auf dem Weg wurde ein Dritter geschädigt. Als Arbeitnehmerin haben Sie grundsätzlich gegenüber Ihrem Arbeitgeber einen Anspruch auf Erstattung der Ihnen durch den Unfall entstandenen Kosten. Dieser Aufwendungsersatzanspruch ergibt sich aus dem Bürgerlichen Gesetzbuch (§ 670). Er umfasst sowohl die Schäden an dem fremden Fahrzeug als auch die Schäden am Fahrzeug des Arbeitnehmers. Das
Bundesarbeitsgericht hat in einem Urteil aus dem Jahre 2006 festgestellt, dass sogar ein Unfallschaden am Pkw des Arbeitnehmers, der auf poröse Reifen zurückzuführen ist, zur Ersatzpflicht des Arbeitgebers führt.

Allerdings ist der Anspruch begrenzt durch ein mögliches Mitverschulden des Arbeitnehmers, der nach den allgemeinen Grundsätzen der Arbeitnehmerhaftung ggf. einen Teil des Schadens selbst tragen muss. Der Erstattungsanspruch des Arbeitnehmers greift nicht, wenn der Arbeitgeber für die Nutzung des privaten Fahrzeugs eine Auslagenpauschale zahlt und diese auch das eingetretene Risiko umfasst. Laut Rechtsprechung des Bundesarbeitsgerichts gilt das dann, wenn die nach dem Steuerrecht mögliche Kilometerpauschale gezahlt wird. In diesem Fall ist laut einem Urteil aus dem Jahr 1992 auch ein Schaden und eine damit verbundene Höherstufung in der Haftpflichtversicherung nicht vom Arbeitgeber zu erstatten. Für die Benutzung eines Pkw beträgt die Pauschale zurzeit
0,30 Euro pro Kilometer, für Motorrad, Moped, Motorroller oder Mofa 0,20 Euro pro Kilometer. Zahlt Ihr Arbeitgeber die Pauschale, muss er Ihnen nichts weiter erstatten.

Zahlt der Arbeitgeber weniger als die Pauschale, gilt es herauszufinden, welche Kosten er pauschal erstattet (zum Beispiel Kraftstoff, Abnutzung), sodass er unter Umständen verpflichtet bleibt, dem Arbeitnehmer die Schäden zu erstatten. Ich empfehle Arbeitgebern immer, in einem Vertrag oder in einer betrieblichen Reisekostenrichtlinie klarzustellen, welche Kosten ihre Pauschale umfasst.

Letzten Endes dürfte der von Ihnen geschilderte Schaden von Ihrer Kfz-Haftpflichtversicherung gedeckt sein. Inwieweit darüber hinaus eine Absicherung möglich ist, hängt von der jeweiligen Versicherung $a b$.

Karsten Bossow

\section{$\Rightarrow$ Wirft auch lhr Berufsalltag rechtliche Fragen auf? Dann schreiben Sie an Simone.Gritsch@thieme.de.}

